\title{
V2me: Evaluating the First Steps in Mobile Friendship Coaching
}

Journal of Ambient Intelligence and Smart Environments, 4 (2012), 517-534

DOI 10.3233/AIS-2012-0177 IOS Press

Author POST-PRINT. Copyright with IOS Press

\author{
Salla Muuraiskangas ${ }^{a},{ }^{*}$, Anja K. Leist ${ }^{\mathrm{b}, \mathrm{c}}$, Andreas Braun ${ }^{\mathrm{d}}$, Kerstin Klauß ${ }^{\mathrm{e}}$, Peter H.M.P. Roelofsma ${ }^{\dagger}$, \\ Reiner Wichert ${ }^{d}$, Peter Klein ${ }^{e}$, and Dieter Ferring ${ }^{b}$ \\ ${ }^{a}$ VTT Technical Research Centre of Finland, Finland \\ ${ }^{\mathrm{b}}$ University of Luxembourg, Walferdange, Luxembourg \\ ${ }^{c}$ Department of Public Health, Erasmus Medical Center, Rotterdam, The Netherlands \\ ${ }^{\mathrm{d}}$ Fraunhofer Institute for Computer Graphics Research IGD, Germany \\ ${ }^{e}$ User Interface Design GmbH, Germany \\ ${ }^{\dagger}$ VUA University Amsterdam, The Netherlands
}

\begin{abstract}
Life events, such as retirement or being widowed, can change the social circle of older people considerably. It may be difficult to find new social contacts when one has never got used to, or perhaps even never learnt, to seek and maintain those contacts. Loneliness has many negative effects for well-being, including depression and even cardiovascular disease. The Ambient Assisted Living Joint Programme (AAL-JP) research project V2me seeks to find a solution for alleviating loneliness by means of easy-to-use technology including touch screen devices. The idea is to use a virtual coach for encouraging users to take an active role in contacting people and teaching them how to initiate and maintain meaningful and enduring relations. The first step, in the process of creating the complete virtual coach-assisted system for preventing loneliness, is to create a prototype and use the feedback from older users for developing the system. In this paper we discuss the results of the first pilot and what steps need to be taken next.
\end{abstract}

Keywords: older adults, loneliness prevention, tablet, virtual coaching, user-centred design.

\section{Introduction}

\subsection{Managing loneliness}

Loneliness can have a detrimental effect on health and well-being [3][10]. It has been shown in various studies that there is a close link between social isolation and negative health-related events, such as cardiovascular disease [11]. This applies even more in old age, when the risk factors for social isolation and feeling of loneliness accumulate [5]. Even though loneliness is a phenomenon perceived almost equally by younger and older age groups, the number of people feeling lonely is higher in very old age [15]. Older people have smaller social networks than younger people [12]. Those closest to them, typically their spouse and friends, are often of a similar age. Due to raised mortality rates of spouses and "old" friends, the risk of loneliness among old people is higher than in other age groups. In line with this, among the most prominent risk factors for both social isolation and loneliness in old age is being single or widowed, compared to being married [44], which affects women to a greater extent than men due to gender-specific 
mortality. Losses have a higher impact on the social network in old age than at a younger age, since it is difficult or even impossible to replace the missing persons. Therefore, to accomplish the major aim of preventing disease and enhancing health and wellbeing in old age, it is vital to reduce feelings of social and emotional loneliness.

From a psychologist's perspective, it has to be considered that social relationships differ in their emotional valence and meaningfulness. This is even more important in old age, when older adults increasingly seek contact with emotionally close people (as elaborated by socio-emotional selectivity theory [12]). It is thus not recommended merely to increase the number or frequency of the social contacts of older adults, but instead to focus particularly on those social contacts that are emotionally significant for them. However, a number of factors impede regular emotionally meaningful social contacts among older adults. The increased mobility of younger generations leads to large geographical distances between older adults and their offspring. As many older adults suffer from chronic diseases and functional impairments that involve reduced mobility [7], it might be difficult for them to get in contact with others.

A solution to these shortcomings is the use of Information and Communications Technology (ICT). Modern technologies not only allow bridging of large geographical distances, but also allow instant messaging, sharing experiences via photographs, videos, and documents, as well as visual contact with others via video chat. These applications help them to stay in contact with others close to you and prevent feelings of loneliness. In order to provide acceptable technology for older people, the basic requirements of this technology are its usability and acceptance, which can be evaluated by studying the user experience related to the technology use or anticipated use [13].

Older adults often do not have the required experience or cognitive and physical abilities to use modern technological equipment like computers. Particularly the generation of 60 years and older have limited knowledge of computers, as these typically were not required in their work place or available in their daily lives [27] [28]. The internet revolution driven by affordable home computer systems and the creation of a worldwide network bypassed the majority of this user group.

Various attempts have been made in recent years to improve the accessibility to modern informationand communication technology for internet users aged over 50. All major operating systems support accessibility helpers, e.g. screen lenses that increase text and image size or text-to-speech engines that read out text to users with poor eyesight. Additionally, there is an increasing market for special applications for older adults, providing a simplified user interface (UI) [17]. A remaining issue is the ubiquitous use of two common interaction devices, the keyboard and the mouse. While they are highly efficient for trained users, they are not very intuitive to people who have rarely used information technology before. The current advent of touch screen technology provides a new opportunity to integrate older adults into the information society by providing an intuitive interaction metaphor that can easily be grasped and that does not require fine motor skills. Studies have shown that older adults are very fast at picking up the skills required to operate a touch screen-based system [32]. Looking at the current trend towards online social networking solutions, these are mostly targeted at people below 50 years of age [26], even though the need for social interaction is still high for older adults. The major online social networks, e.g. Facebook, are aimed at younger adults, and provide a plethora of features that may be overwhelming to older adults. These factors often prevent older adults from actively participating in those communities. There are online social networks targeted specifically at older adults, e.g. Eons.com [18] or oldkids.cn [35]. However, they still require a regular browser for operation and thus are mainly interesting for technically adept persons. In addition, these kinds of solutions are only feasible for older adults who have emotionally meaningful social relationships. To conclude, first, there is a need to create social network solutions for older and technically less adept users. Second, the existing solutions cannot be used when there is a lack of emotionally meaningful relatives, friends or acquaintances. There is a need to find solutions to alleviate loneliness among older adults who lack emotionally meaningful social relationships.

There are several reasons why it might be difficult for older adults to find new friends. Outsized expectations, for example, of what a friend should or should not be, can be overcome by learning about different meanings of the word "friendship". Older adults who might have problems getting in contact with new acquaintances might benefit from learning about mechanisms for making friends and to acquire the abilities for getting in contact with others. Group interventions, for example friendship enrichment programmes aiming for decreasing loneliness, have been proved to be effective [30][42]. However, one might fail to reach people who cannot leave their 
home any more. Also, group interventions only last a limited time span, and it is not possible for the users to engage in continuous friendship training. One solution to both these shortcomings is to use a virtual coach-assisted friendship enrichment programme that allows home-bound people to engage in continuous training. The virtual coach could additionally mediate between users and computers and thus bridge the gap in technological knowledge.

Virtual coaches can play a crucial role for persuading and motivating people for behavioural change. They are becoming important factors in different media environments and are suitable for different purposes [25]. Virtual coaches can be understood as "computer systems capable of sensing relevant context, determining user intent and providing useful feedback with the aim of improving some aspect of the user's life" [21]. They give advice about decisions and give compliments and comforting words in order to motivate people.

Research studies elucidate that virtual coaches and agents help to motivate people to learn and finish certain activities [9]. Research from Eyck et al. [16] and Westerink et al. [45] showed that virtual coaches motivate people to exercise more and better. To facilitate motivation, Baylor [9] points out that the virtual coach does not only have to have a voice, but has also to be physically present either as a real person on a screen or as an avatar, a computer-generated graphical representation of a human being. Secondly, she states that the virtual coach has to be adapted to the target audience, which means that it should be attractive to the users of the system.

Both the Social Cognitive Theory [8] and the Theory of Reasoned Action from Fishbein and Ajzen explain that motivational factors are the indicators of how much effort people want to put into actions and tasks in order to perform certain behaviour [20]. Motivation always implies individual needs and goals, since a person is motivated if he or she seeks to satisfy a need and follows a specific goal associated with this. Ajzen [2] and Bandura [8] [46] argue that motivation increases the certainty of performing a specific behaviour. Thus, the more motivated people are to have social contacts, the more the certainty exists that they are eventually performing the behaviour such as initiating and maintaining social contact. High selfefficacy, that is, belief in your own abilities to succeed in what you are doing, can further motivate you to perform a certain activity [8][19]. Frost et al. [22] demonstrated that intrinsic motivation can be increased by the parasocial interaction with virtual coaches. The parasocial interaction is the feeling of being in personal interaction with a displayed media character [23]. This parasocial interaction makes the person wish to be in further contact with the media character, and this increased engagement can also be a reason why people are motivated by it [23]. Previous literature also states that, when a character gives compliments, shows emotions, talks personally and is displayed closely to the viewer, this leads to higher levels of parasocial interaction [6] [23] [31] [40].

Therefore, a technological solution aiming both at providing (a) an intervention tool to learn how to make new friends, and (b) motivational functionalities to get and stay in contact with others, is highly desirable to alleviate feelings of loneliness and thus enhance the health and well-being of older adults. In order to be efficient, the proposed technological solution should be user-friendly, preferably a touch screen device, and contain coaching both in the use and in friendship enrichment.

\subsection{Background to the V2me project}

V2me (Virtual coach reaches out to me) is an Ambient Assisted Living Joint Programme (AAL JP) project that aims to improve the quality of life through social networking activities [43]. A combination of encouraging the user through virtual coaching and providing an intuitive interaction between older adults and online communities is the driving force of the project and is a promising approach to including older adults into the information society.

The idea for the V2me project arose within another AAL JP project called $\mathrm{A}^{2} \mathrm{E}^{2}$ (Adaptive ambient empowerment of the elderly). $\mathrm{A}^{2} \mathrm{E}^{2}$ is working on a virtual-coach-assisted system to support lifestyle behaviour changes for management of diabetes type II and cardio-vascular diseases [1]. The $\mathrm{A}^{2} \mathrm{E}^{2}$ system focuses on improving quality of life by supporting exercise behaviour changes with the help of a 3D virtual coach. The system is implemented in an internetconnected device, e.g. an all-in-one PC with touch screen, located in the older person's home. The static part has the function as a home platform. The idea in V2me is to extend the $\mathrm{A}^{2} \mathrm{E}^{2}$ system with aspects of social behaviour change tackling the problem of loneliness. Concretely, it means that the $\mathrm{A}^{2} \mathrm{E}^{2}$ provides the home platform with a graphical virtual coach, and V2me extends the system with the services for loneliness prevention, such as social network and communication facilities as well as interfacing external services. Another important part of the system is the 
accessibility via a mobile device, the so-called mobile platform.

The mobile platform will act as main interaction device, like a remote control, for using the services provided and controlling the system. Also, the actions performed in the mobile platform could be followed by the virtual coach's reactions on a bigger full screen of the home platform also allowing improved graphical presentation and speech output. The mobile platform can be used both in the user's immediate environment and outside their homes. Both home and mobile platform will be communicating either directly with supported web services or indirectly through the controlling servers that host the services required for social networking.

While the home platform was still under development in $\mathrm{A}^{2} \mathrm{E}^{2}$, V2me started with the development of the mobile platform and the selected services, including the virtual coach logic and its presentation.

\subsection{Study goals}

This study reports the first step results where the prototype of the V2me system and the selected service scenario have been created for loneliness prevention for a tablet, and tested. This paper presents the development process and findings of user experience and user acceptance of such a technology for deriving the requirements for a system with social networking and friendship functionality. Additionally, the study was carried out to validate whether the first prototype can achieve the main goals of the V2me project in terms of providing a well-accepted system.

\section{Materials and methods}

\subsection{User-centred design for older users}

The needs and limitations of the target group give important indications for the development of an intuitive and user-friendly system which is one precondition for overcoming the often observed reluctance to use modern ICT in the target group of older adults. Therefore, a user-centred design (UCD) process is used in the development. The UCD process structures the development process in the V2me over four iterative phases: analysis, design, prototyping and testing [24]. In the analysis phase, requirements can be derived based on the information from and about the target group. In the design phase, these requirements are implemented in a screen and interaction design.
In the prototyping phase, a prototype is created based on the design produced. Finally, in the testing phase, the current status of the system is evaluated with endusers. Using an actual system enables potential users to really test and experience the envisioned concepts. The feedback of the users is valuable for the further development and optimization of the system.

The scenario-based design approach by Rosson and Carroll uses scenarios and personas in order to translate requirements into concrete stories with typical users [38]. This enables one to focus on the user and helps to bridge misunderstandings caused by different terminology in a multidisciplinary team. These scenarios are continuously extended throughout the whole development process, becoming more and more detailed.

\subsection{Requirement analysis}

The V2me project started with a detailed analysis phase, in which information on the target group was gathered and, based on that information, user and system requirements were derived laying the foundation for the subsequent development activities.

Two complementary methods were selected to gain a deeper understanding of the target group, including their needs, mental and physical limitations, as well as a social context of use in which they will interact with the system:

1. Face-to-face interviews (30 in total) with the residents of care centres and assisted living accommodation units of a care provider in South Germany (Diakonie Neuendettelsau)

2. Two workshops each with 5 professionals from the specific care provider and other care institutions.

Thereby, input from two different stakeholder groups complemented the picture of the target group's requirements from two different perspectives: the perspective of the older user and the perspective of the professionals who are interacting with the target group every day.

\subsubsection{Scenarios}

Three scenarios were developed for the requirement analysis:

1.Loneliness prevention - Finding an interest group with the help of the virtual coach. In this scenario the virtual coach helps in finding friends through appropriate groups.

2. Staying active longer through shared exercising allowing the users to train together in a virtual 
fitness room where they can communicate with each other, thus increasing motivation.

3. Interactive event planning. This scenario is an expanded calendar function in which the virtual coach suggests events based on the user profile and those events can be shared with friends in the networks

Each scenario described a short course of interaction in a slide show - each slide showing one step in the process.

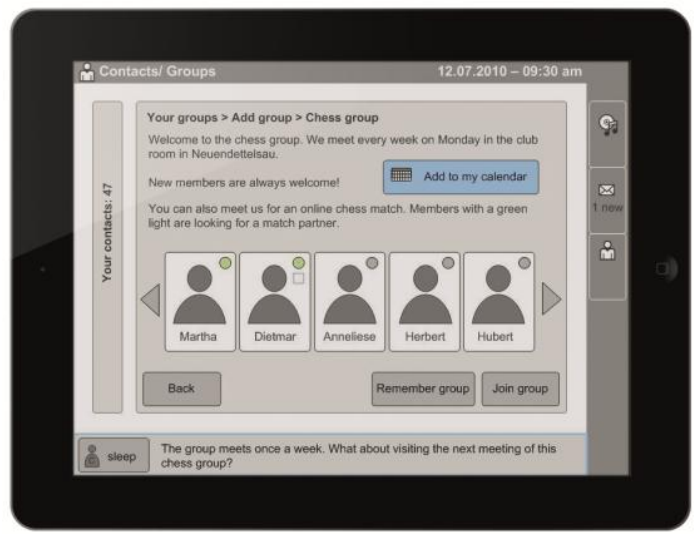

Fig. 1. Mock-up of initial interviews and workshops

\subsubsection{Conducting the face-to-face interviews}

A total of 30 participants were recruited based on the following recruiting criteria: (1) aged 65 and older, (2) usage of modern technologies (at least a telephone, mobile phone or even a PC), (3) open to new things, (4) existing social integration or desire to be socially integrated, (5) looking for new activities.

The recruited and interviewed sample consisted of 30 participants aged between 69 and $90\left(\mathrm{M}^{1}=80.50\right.$, $\left.\mathrm{SD}^{2}=5.26\right) .19$ were female. The participants used classic ICT, such as telephone, TV and radio. Only about half were using a mobile phone and a quarter were using a computer and the internet. Applications like Facebook and Skype were mostly unknown.

All 30 face-to-face interviews took between 1.5 and 2 hours, which allowed accommodation to the individual pace and state of concentration of each participant, or the heterogeneous knowledge of modern ICT of the elderly participants.

The interviews were semi-structured and built up along four content dimensions that were determined to be of central importance in identifying user re-

\footnotetext{
${ }^{1} \mathrm{M}=$ mean

${ }^{2} \mathrm{SD}=$ standard deviation
}

quirements. The choices of these contents relied on literature review and on the experience of former projects [37]:

1. Socio-demographic variables were assessed, including age, gender, marital status, number of children and grandchildren as well as educational training and vocational activities. The questionnaire also included health-related selfassessments.

2.ICT Usage: A list of 12 information and communication technologies (e.g. telephone, e-mail, Facebook) was shown to the interviewees and they had to rate whether they use this technology or whether this technology is unknown to them.

3. Estimated usefulness of proposed technologies: Items were created in accordance with selected use cases. Each item asked for the individually perceived usefulness of the respective technology presented. These items were rated on a 5point scale ranging from (1) - "not useful at all" to (5) - "very useful".

4. General attitudes toward technology: A total of seven items asked for generalized attitudes to modern ICT and issues that might arise with their use (e.g. privacy). Further items asked for the respondent's perceived own sociability and openness to new experiences. The items consisted of statements, and the respondents had to rate on a 5-point scale whether the item applied to them or not (range: (1) - "doesn't apply at all" to (5) - "totally applies").

Both in the face-to-face interviews and in the workshops, preliminary low-fidelity mock-ups were presented as paper prints to obtain a first feedback on the V2me vision. The mock-ups were created of the first scenario "Finding an interest group with the help of the Virtual Coach" (Figure 1). The design-free mock-ups were created with a wireframing tool (Microsoft Visio) for a 10-inch tablet based on two personas.

The participants were asked to tell the interviewer how they expected to perform a short task (join a group of people with common interests) with the paper mock-up. Using standardized items, the mock-ups were afterwards rated by the participants on six dimensions: (1) comprehensibility, (2) appeal of the design, (3) usefulness of the virtual coach, (4) ease in following the instructions of the coach, (5) rating of the total system, and (6) use in everyday life. Openended questions were used to give the respondents the opportunity to add their suggestions and to gain a better understanding on their problems with, and acceptance of, the current UI mock-up. 


\subsubsection{Conducting the workshops with professionals}

The two workshops were conducted with two different groups of professionals who work for social service providers: (1) 5 institution managers ( 3 male, 2 female) and (2) 5 staff members (coordinators, nursing leaders) from the Diakonie Neuendettelsau and other social service providers ( 2 male, 3 female). The different groups were invited to separate sessions to avoid bias caused by hierarchy affects.

The workshops were mainly based on the brainwriting technique which allows one to work out a lot of ideas on open-ended questions, and also to make use of the reciprocal inspiration of the participants

Both workshops lasted for 3 hours (with a short break) and were structured along workshop guidelines which can be divided in four parts:

1. The first part of the workshop focused on the current acceptance of current activities and services offered to the elderly residents to obtain more information about related needs, problems and difficulties. Facilitating as well as hindering factors were collected.

2. In the second part of the workshop all three preliminary UI mock-ups were presented (1) via a beamer with a description by the moderator and (2) as slide show (without textual description) on an iPad, which allowed the participants to get a better impression of the V2me vision. Feedback was gathered afterwards.

3. The third and central phase mainly focused on creating solutions to problems and difficulties identified (1) related to current activities and services, and (2) related to the UI mock-ups. The focus of the solutions was specifically on the means of modern technologies.

4. Finally, in the fourth part of the workshop the results of the workshop were revisited and weighted by the participants, who wrote down the most important aspects that should be kept in mind when developing an interactive system for elderly people, and weighting the consolidated list with self-adhesive stickers.

\subsubsection{Analysis}

In the next step the quantitative and qualitative data gathered from the interviews and the workshops was evaluated and analysed. Qualitative data was analysed by means of qualitative content analysis to cluster the data into common topics and categories.

\subsubsection{Results and Requirements}

The results of both interviews and workshops are in line with the current literature on the use of ICT by elderly users.

Concerning the functions, the results showed that the participants rated functions that offer social activities and are expected to enhance social embedding like getting to know people with similar interests with slightly higher scores than other functions.

1. This confirms the concept of the virtual coach as a parasocial relationship.

2. Furthermore, it strengthens the necessity to focus on scenarios along the friendship enrichment programme of the Free University of Amsterdam [30].

Further, the results gave input for better specifying the target group.

1. A high inter-individual variability was measured concerning general attitudes towards ICT; this heterogeneity in our target group emphasises the need for an adaptive system.

2. Also a positive correlation between the estimated usefulness and openness to new experiences and sociability was found: participants who described themselves as being open-minded had an increased tendency to rate the proposed technologies as useful. The V2me system should therefore target older people who consider their social situations and who actively seek to widen their social networks as they are expected to benefit most from such a system.

Moreover, requirements for the V2me system were derived, based on the analysed data from the interviews and workshops as well as on the input of a detailed state-of-the-art analysis. The derived requirements can be clustered into the following categories:

1. Connecting system that supports communication with friends in the network.

2. Entertaining system that is enjoyable to use, e.g. by providing games with multiple users of the network.

3. Informative system that gives the user access to necessary or desirable information.

4. Simple (to use) system that is intuitively usable and does not require pre-existing knowledge of computers.

5. Intelligent system that naturally reacts to the user and anticipates possible actions.

6. Motivating system that facilitates usage through motivating the users, e.g. by using a virtual coach.

7. Adaptive system that can be individually configured to user preference and different needs. 
8. Reliable system that does not need high levels of maintenance and is acting in a predictable and reliable way.

In addition to a tabular description, the information on the target group was used to adapt the two personas written in the analysis phase and to list a number of old and new scenarios covering the main functions to be implemented in this project in order to make the requirements applicable, testable and traceable.

\subsection{Interaction and screen design}

The challenge of the second phase of the UCD is to implement the requirements defined in the analysis phase in an interaction and screen design. At the beginning of the V2me project, a bigger tablet device was considered for use as a home platform, and an additional smartphone as a mobile platform. Later it was decided to use touch screen PC as the home platform and merge the tablet and smart phone into a small tablet device of the 7-inch class that combines portability with a sufficient screen size for our application.

Designing for a tablet, in comparison to a PC, is challenging, because there is a limited space available that can be used to display information. However, a tablet also offers many benefits. Due to its relatively small size and low weight, the device is portable and thus can be used almost anywhere and anytime, and that way the virtual coach can be totally immersed into the user's environment. Also, the compact size enables interacting with the device in various postures, e.g. holding the device on a table, in the hands and on the lap, preventing strain on single muscles. In combination with other devices, such as a PC, it may act as a remote control. At this first testing stage, no interaction between mobile platform and home platform was realised.

The interaction design concept is underlined by two requirements derived from the analysis: "Keep the UI simple" and "Provide a central control with a consistent UI". In addition to the results of the analysis phase, the prototype was designed based on the established design principles for older users that include "minimize irrelevant screen information" or "clearly label keys", for instance [41].

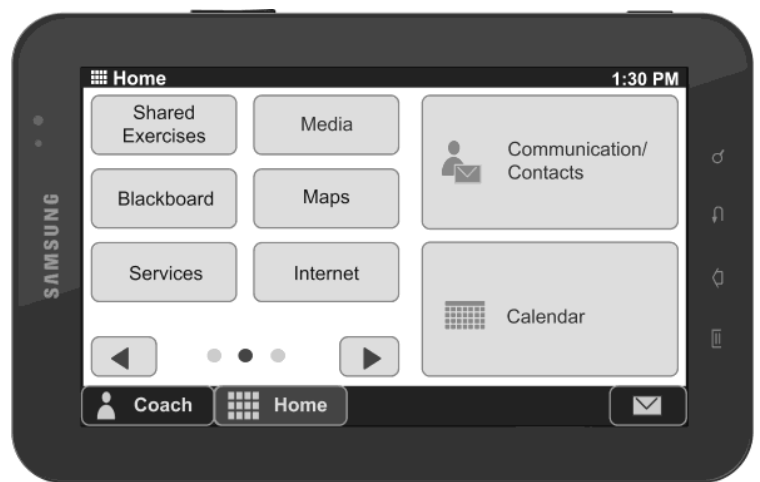

Fig. 2. Wireframe of Home menu

Based on the requirement analysis, the scenario with the most frequent interaction with the virtual coach (Loneliness prevention - Finding an interest group with the help of the virtual coach) was selected to form the basis for the interaction and screen design concept. Therefore, content from two exemplary sessions of the friendship enrichment programme [30] was adapted and integrated into the first scenario.

In the first step, the description of the selected scenario was expanded into an information scenario with our male persona. The persona and scenarios help to design from the user's perspective. Based on this process, a screen layout, screen types und basic interaction patterns were defined and converted into digital wireframes (example in Figure 2). Using design free wireframes allows the illustration of early concepts with minimum effort and prevents the team from sticking to the concept details too early.

In the next step, the still textual information scenario was expanded into an interaction scenario by adding wireframes and descriptions concerning possible interactions on each screen. Furthermore, a screen design was created on the defined screens and the requirements defined by the interaction scenario.

To achieve a high contrast between background and font and based on the requirement that the contrast should also work in a mobile and outdoor scenario, a dark background in combination with a bright font colour was chosen. The final screen design and contrast differences can be seen from the screen design in the Figure 3.

Also, it is important to find a non-stigmatizing design style for addressing the whole user experience without compromising usability. This means that the system should not contain exaggerated font sizes but should, for instance, enable increasing the font size; it should not contain exaggerated button sizes, but could still contain a larger touchable area around the buttons. 


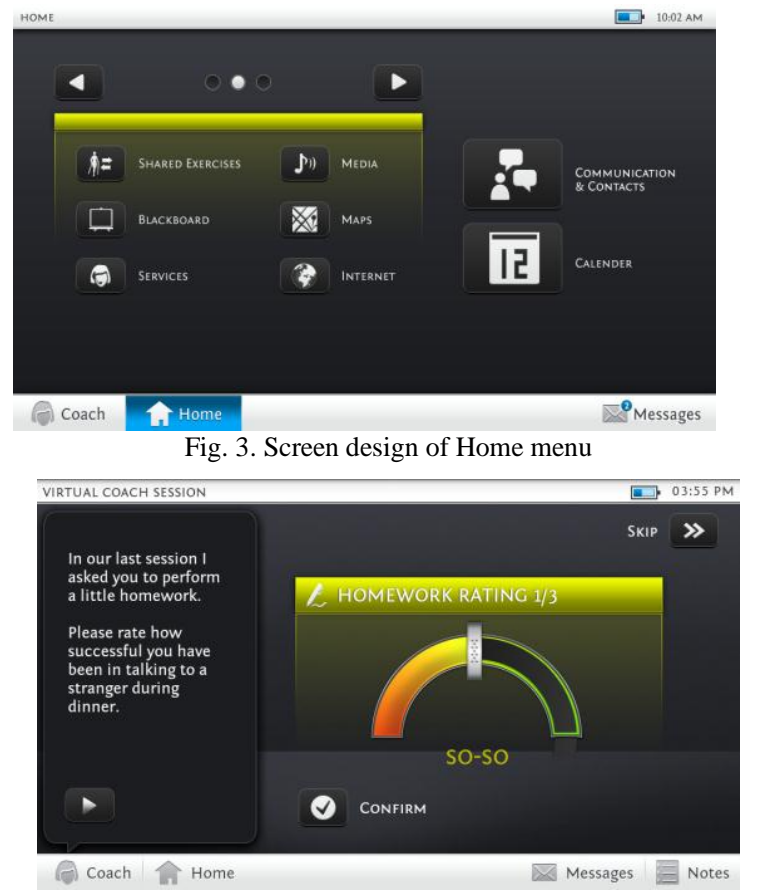

Fig. 4. Virtual coach and rating homework with Tacho control

\subsection{Virtual coach design}

In the V2me system, the coach plays a central part since it is the mediator between the user and the system. Two different representation levels are considered: (1) textual representation with a static icon of the coach (Fig. 4) and (2) a graphical emotionally expressive 3D representation by a full or upper body rendering according to the application which will be developed later in the home platform. The system communicates with the user via text-to-speech synthesiser. The virtual coach actions in the mobile and home platform are synchronised using a persistent connection between both platforms resulting in actions performed on the tablet causing an effect in the $3 \mathrm{D}$ coach presentation in the home platform. In this paper we focus on the mobile platform and, therefore, on the textually represented virtual coach.

The virtual coach can take on various roles, as (1) mentor, (2) friend and (3) expert. It is a mentor when guiding and teaching additional skills to the user, such as how to make friends based on the friendship enrichment programme. The coach is a friend by just being there and "conversing" with the users. This role is important for creating a parasocial relationship between the system and the user, and therefore reduc- ing any anxiety the user might have about the modern technology, to build a confidence between the system and the user and increase the motivation for using the system. In the expert role, the virtual coach gives the information the user desires, e.g. lists events of interest to the user or information how to proceed in the system.

One important lesson learned from the user requirements phase is that the virtual coach's support should adapt according to the required help or privacy. Therefore the virtual coach can either act as a proactive coach who motivates getting in contact, or it can be set in the background or even be completely deactivated. The virtual coach's actions can be timetriggered or started by the user. When the coach speaks, the spoken text is displayed on the screen and the user is able to repeat the speech in case he did not hear it properly by tapping the repeat button in the bubble.

Furthermore, the virtual coach is designed to learn. Therefore the virtual coach gathers further information about the user during the interaction by asking questions, for instance about user's mood or reason not to join a proposed event (all answers from the user are voluntary). This allows the virtual coach to react more and more adequately with the user and user's specific needs.

A range of functionalities of the virtual coach is required for creating a system for social behaviour change. Table 1 presents possible functionalities categorised according to the persuasive system design (PSD) framework compiled by Oinas-Kukkonen and Harjumaa Error! Reference source not found.. To create a persuasive system, it should attempt to fulfil the majority of the categories. The implemented functionalities are marked there and also the functionalities that pose difficulties in implementation. The table shows that there is a whole range of functionalities that could improve the persuasiveness of the system further.

The following scenario was introduced in the pilot study and illustrates the existing coach functionalities:

It is 10 o' clock in the morning and you come back from breakfast to your living room. Some weeks ago the V2me system has been installed in your living room. Coach Peter from then on accompanies you through the day. As you want to make some new contacts, the staff from the care centre have activated the friendship enrichment programme on the tablet for you. This programme focuses on making new contacts. So Coach Peter helps you make new friends by leading you step by step through a number of ses- 
sions. In each session you go through some exercises like talking about your idea of friendship or getting in contact with other people. In the last session you are given the homework task by Coach Peter to talk to a stranger in the cafeteria. You successfully managed to talk to somebody.

The virtual coach guides the user on, for example, how to converse with people. The guiding sessions, workflows, consist of various pages where the coach asks a question and provides several pre-formulated answers. The text is transformed into speech with a text-to-speech synthesiser.

Table 1

The persuasive functionalities of the virtual coach and the system

\begin{tabular}{|c|c|c|}
\hline Functionality & PSD principle & $\begin{array}{c}\text { Imple- } \\
\text { mented }^{3}\end{array}$ \\
\hline $\begin{array}{l}\text { Suggests social events and people to contact } \\
\text { reducing the effort in finding friends }\end{array}$ & 1. Reduction & - \\
\hline $\begin{array}{l}\text { Teaches the user social skills in workflow- } \\
\text { based lessons }\end{array}$ & 2. Tunnelling & Y \\
\hline $\begin{array}{l}\text { Provides interesting reminders and sugges- } \\
\text { tions related to social life. Learns the user's } \\
\text { preferences based on the previous choices. }\end{array}$ & 3. Tailoring & - \\
\hline $\begin{array}{l}\text { Coach presentation, UI and how the infor- } \\
\text { mation is displayed can be adapted }\end{array}$ & 4. Personalisation & - \\
\hline $\begin{array}{l}\text { Tracks e.g. one's social activity and } \\
\text { achieved friendship goals }\end{array}$ & $\begin{array}{l}\text { 5. Self- } \\
\text { monitoring }\end{array}$ & - \\
\hline $\begin{array}{l}\text { Distributes real stories of the users of the } \\
\text { system }\end{array}$ & 6. Simulation & - \\
\hline Trains social situations with the user & 7. Rehearsal & $\mathrm{Y}$ \\
\hline $\begin{array}{l}\text { Appraises after successful action, home- } \\
\text { work, achieved goal, etc. }\end{array}$ & 8. Praise & Y \\
\hline Gives virtual trophy or reward & 9. Rewards & - \\
\hline Reminds about personal goals & 10. Reminders & - \\
\hline Suggests initiating communication & 11. Suggestion & $\mathrm{Y}$ \\
\hline $\begin{array}{l}\text { Speaks the language of the older person. } \\
\text { Is presented graphically as an older person }\end{array}$ & 12. Similarity & $\begin{array}{l} \\
-\end{array}$ \\
\hline Attracts visually & 13. Liking & $\mathrm{Y}$ \\
\hline Is virtual talking character & 14. Social role & $\mathrm{Y}$ \\
\hline $\begin{array}{l}\text { Highlights that the advice is supported by } \\
\text { the psychologists }\end{array}$ & $\begin{array}{l}\text { 15. Trustworthi- } \\
\text { ness }\end{array}$ & - \\
\hline Highlights the core knowledge of the coach & 16. Expertise & - \\
\hline UI looks professional & $\begin{array}{l}\text { 17. Surface credi- } \\
\text { bility }\end{array}$ & Y \\
\hline $\begin{array}{l}\text { Provides contacts with real people (e.g. } \\
\text { friends) and enables contacting them. } \\
\text { Provides information on real events. }\end{array}$ & $\begin{array}{l}\text { 18. Real-world } \\
\text { feel }\end{array}$ & - \\
\hline $\begin{array}{l}\text { Refers to a prestige psychologist or institute } \\
\text { that confirms the importance of the system }\end{array}$ & 19. Authority & DI \\
\hline $\begin{array}{l}\text { Displays the certificates the system has been } \\
\text { awarded }\end{array}$ & $\begin{array}{l}\text { 20. Third-party } \\
\text { endorsements }\end{array}$ & DI \\
\hline $\begin{array}{l}\text { Provides links to websites that support the } \\
\text { approach and provided information }\end{array}$ & 21 Verifiability & DI \\
\hline
\end{tabular}

${ }^{3}$ Note for the coding: Y - yes, DI - difficult to implement

\begin{tabular}{lll}
\hline $\begin{array}{l}\text { Provides experiences of others making } \\
\text { friends using the system }\end{array}$ & $\begin{array}{l}\text { 22. Social learn- } \\
\text { ing }\end{array}$ & - \\
\hline $\begin{array}{l}\text { Provides statistics of the activity of one's } \\
\text { friends using the system }\end{array}$ & $\begin{array}{l}\text { 23. Social com- } \\
\text { parison }\end{array}$ & - \\
\hline $\begin{array}{l}\text { Creates groups with same friendship goals } \\
\text { and same interest }\end{array}$ & $\begin{array}{l}\text { 24. Normative } \\
\text { influence }\end{array}$ & - \\
\hline $\begin{array}{l}\text { Provides information that other people are } \\
\text { trying the same }\end{array}$ & $\begin{array}{l}\text { 25. Social facilita- } \\
\text { tion }\end{array}$ & - \\
\hline $\begin{array}{l}\text { Provides peer-support for people in a simi- } \\
\text { lar situation via interest group }\end{array}$ & 26. Cooperation & - \\
\hline $\begin{array}{l}\text { Offers competition with a number of friends } \\
\text { (unethical?) }\end{array}$ & 27. Competition & DI \\
\hline $\begin{array}{l}\text { Provides public recognition of the people } \\
\text { achieving their friendship goals }\end{array}$ & 28. Recognition & - \\
\hline
\end{tabular}

\subsection{Prototyping}

The prototype was implemented using the Android software development kit in Java programming language. The software prototype is optimised for 7-inch Android tablet running Android 2.2. Java framework Simple is used for XML serialization. In the testing, the Samsung Galaxy Tab GT-P1000 as end device and commercial Loquendo for speech synthesis were used.

The UI created is a blend of the Android UI elements provided by the system [4] and custom elements that have been created specifically for this application and aimed at improving the usability for the older adults. The application is running in full screen on the tablet. The UI contains some complex controls that are implemented as custom controls like (1) the Carousel Control, which is used to display groups and persons, (2) the Tacho Control, which allows the user to answer a question and choose between different answer options, and (3) the Bubble Control \& Loupe Control, which controls the speech output and is used to display the text, spoken by the virtual coach. The bubble controls are simple views with background images and a repeat button, the loupe control splits the text into equally long parts, to display these with a readable font size.

\subsection{Evaluating user experience and acceptance}

User experience (especially related to ease-of-use) and user acceptance tests are central elements in the UCD process, as they integrate with the real user, whereas personas and scenarios still give room for interpretation. User experience is "person's perceptions and responses that result from the use or anticipated use of a product, system or service" [24]. According to Davis' model of technology acceptance (TAM), perceived ease-of-use and perceived useful- 
ness which are both components of the widely used term "user experience", can be used to predict user acceptance [13]. By studying these user experiences we receive valuable information about the system and the user acceptance related to it. However, Davis' usefulness items in particular do not fit very well into the lives of older people who perhaps do not consider work efficiency to be their main motive.

Two well-established methods were chosen in order to evaluate ease-of-use, usefulness and user acceptance of the prototype: formative one-on-one usability tests and a workshop. These methods gather mainly qualitative data [34]. Qualitative data makes it possible to understand the reasons why a usability issue has occurred, how the user's mental model looks like and what the user would have expected instead. This deeper understanding enables the team to derive recommendations and iteratively optimize the system.

\subsection{Testing procedure}

The overall aim of the testing procedure was first to gain information on how older users interact with a tablet, perceive the system and what their general wishes and needs are in interacting with a virtual coach. Before testing, a background questionnaire was sent to the participants to be completed before testing. The background questionnaire was used for collecting data about age, marital status, self-rated health, loneliness (using the short loneliness scale of de Jong Gierveld and van Tilburg [14]) and experience of ICT. The background information is displayed in Table 2. In accordance with ethical standards in social science research, informed consent was established and sent to the participants in advance.

One-on-one usability test sessions concentrated on gathering data about ease-of-use. Sessions consisted of the following three phases:

1. Introduction phase, in which short introductory questions were used to relax the participants,

2.Testing phase, in which participants worked through three tasks with the V2me prototype on the tablet while "thinking aloud", and

3. Final phase, in which moderator made a final interview to sum up the test.

At the beginning of the introduction phase, each participant was given a short description of the V2me system, which concentrated on the vision of the project, but neither included any information on how the system works nor any training on the tablet. Furthermore, the introductory questions were used to re- check the screening criteria and make the participants feel comfortable. The testing phase consisted of three tasks during which the interaction with the device was observed. In the first task, the participants were asked freely to describe their expectations of the system. They also held the device in their hands and looked at the screen, explaining what they could see. Participants rated the ease of reading the text using a 5 -point scale from very easy to very difficult. In the second task, the participants were asked to follow the virtual coach through an adapted friendship lesson realised for the tablet (the scenario description given can be found in 2.4). Users rated their mood and the imagined homework and paged through interest groups. The participants were asked to rate ease of hearing the coach's speech and ease of the task using a similar 5-point scale as in the first task. In the third and final task, the participants disabled the virtual coach so that it would not talk anymore. The participants rated the ease of completing the task with a 5point scale. They were also asked two open questions about the coach's status. The final interview was developed gathering suitable items from the TAM and creating questions related to user experience and intended use using Likert scales. Also, open questions were asked about generally positive as well as negative feedback on the V2me system. The replies for the user experiences are presented in Fig. 5.

As the one-on-one sessions concentrated on usability, the workshop was intended to discuss about functionalities and whether the prototype was experienced as useful. The workshop was structured in the following five phases:

1. Opening phase, where participants were welcomed and the moderator tried to make them feel comfortable,

2. Introduction phase, where participants introduced themselves and discussed their previous experiences of technology,

3. Transition phase, where the V2me project and prototype were introduced,

4. Key phase, where participants familiarised themselves with the prototype and then discussed it in the group, and

5. Final phase, where the workshop was concluded.

Table 2

Socio-demographic characteristics

One-on-one Workshop Total 


\begin{tabular}{|c|c|c|c|}
\hline & M (SD) & M (SD) & \\
\hline Participants $[\mathrm{N}]$ & 6 & 7 & 13 \\
\hline Age [years] & $78.8(9.0)$ & $80.6(6.1)$ & $79.8(7.4)$ \\
\hline Females [\%] & 50 & 100 & 76.9 \\
\hline Living alone [\%] & 50 & 100 & 76.9 \\
\hline Degree of loneliness & $3.2(3.0)$ & $1.9(2.3)$ & $2.4(2.6)$ \\
\hline Self-rated health & $3.8(0.4)$ & $3.9(0.9)$ & $3.9(0.7)$ \\
\hline $\begin{array}{l}\text { Openness to } \\
\text { technology }\end{array}$ & $16.8(2.1)$ & $13.0(3.1)$ & $14.8(3.2)$ \\
\hline
\end{tabular}




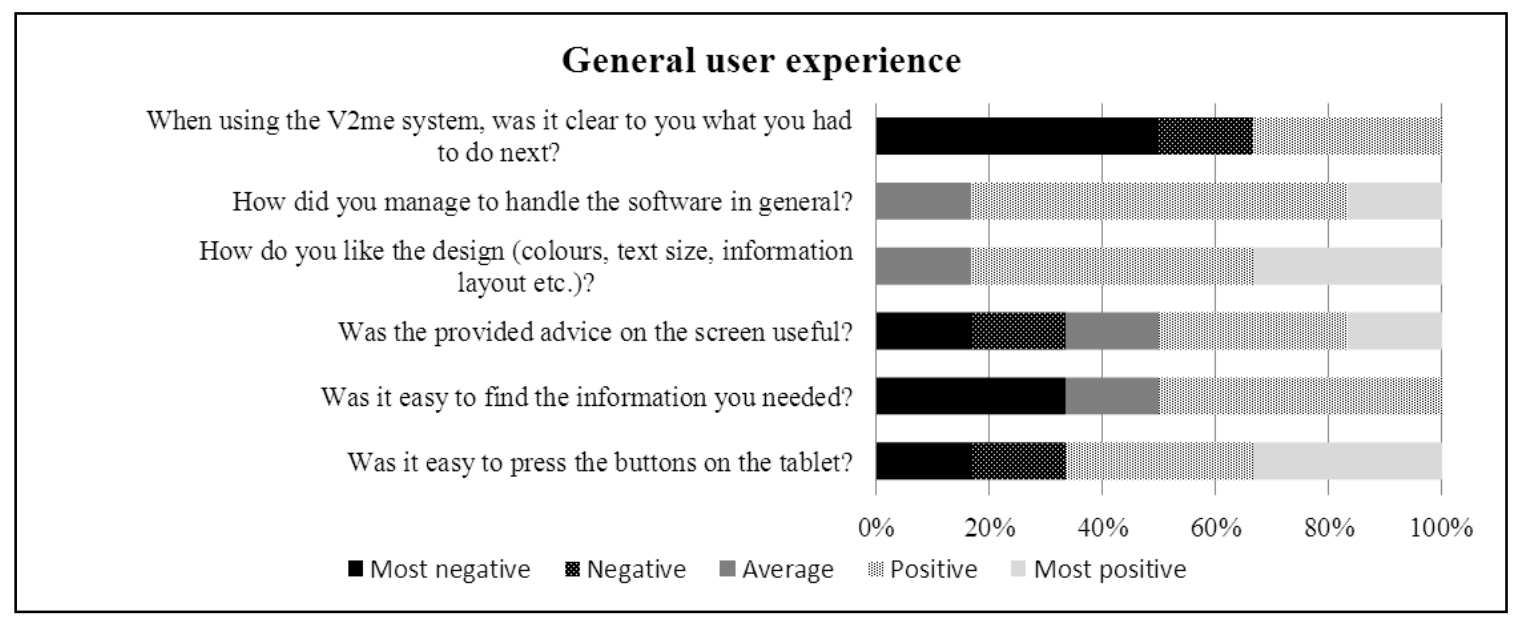

In the key phase, the prototype was introduced and participants were divided into groups of two or three with one research assistant. In every group there was one experienced and one less experienced PC user. After being able to freely try out the prototype, a structured group discussion was held covering different aspects. It was discussed whether the proposed features fit normal behaviour patterns, what additional functions there could be in the system, user experience, ease-of-use and usefulness of the system, usefulness of virtual coach, UI, accessibility and potential improvements for the system.

One-on-one sessions and workshop were recorded. The data was transcribed and analysed. Data-analysis was conducted, applying a problem-centred approach.

\subsection{Socio-demographic characteristics}

One-on-one usability test sessions were conducted with six participants (aged between 66 and 88, M = 78.8, $\mathrm{SD}=9.0$ ) at the Nellestein Centre (Care Centre) and the Free University of Amsterdam. Each session lasted about 90 minutes. Half of the participants were female. Three of the participants were married, two widowed and one unmarried. Health was rated as 3.8 on average $(\mathrm{SD}=0.4)$ on a scale from 1 'very bad' to 5 'very good'. According to the short loneliness scale, three of the participants were moderately lonely to some extent $(\mathrm{AVG}=3.2, \mathrm{SD}=3.0$ ). The scale is from 0 to 12 , where 0 to 2 stands for 'not lonely', 3 to 8 for 'moderately lonely', 9 to 10 for 'severely lonely' and 11 to 12 for 'very severely lonely'.

In addition to the one-on-one sessions a workshop was conducted at the Nellestein Centre with seven participants (aged between 74 and 89, $\mathrm{M}=80.6, \mathrm{SD}$
= 6.1) who familiarised themselves with the prototype and discussed it. The workshop lasted about 90 minutes as well. All of the workshop participants were female. Two of them were divorced, four widowed and one unmarried. Health was rated analogous and resulted in 3.9 on average $(\mathrm{SD}=0.9)$. According to the short loneliness scale, three were moderately lonely $(\mathrm{AVG}=1.9, \mathrm{SD}=2.3)$. Demographic characteristics of the participants are described in Table 2.

Both groups were relatively open to new technology. The one-on-one group scored an average of 16.8 (SD 2.14) and the workshop group scored somewhat lower $(\mathrm{AVG}=13.01, \mathrm{SD}=3.08)$. The scores from the 'openness to technology scale' rank from 'very open' (20-24); to 'open' (16-19); 'open but needs more convincing' (12-15), 'not open' (7-11) and 'very unopen' (4-6).

\section{Results}

The results from the one-on-one sessions and the workshop were evaluated and analysed. The following chapters describe issues identified concerning the perceived ease-of-use (received mainly from one-onone sessions) and usefulness (received mainly from the workshop), as well as the acceptance (overall conclusions of the tests) of the current prototype. Quotes are mainly obtained from the workshops. The derived requirements are coded and presented in Table 3 for having clearer idea where the requirements are derived and what issue it tackles. 
Table 3

Requirements for mobile friendship coaching

\begin{tabular}{cl}
\hline R1 & $\begin{array}{l}\text { Consider the weight of the system: a light system is } \\
\text { considered more important than a large screen, espe- } \\
\text { cially when the system is intended to be carried around }\end{array}$ \\
\hline T2 & $\begin{array}{l}\text { If possible choose a tablet that does not have physical } \\
\text { keys in inconvenient places where they might disturb } \\
\text { the use }\end{array}$ \\
\hline T3 & $\begin{array}{l}\text { Use non-reflecting screens or an anti-glare screen pro- } \\
\text { tector if necessary }\end{array}$ \\
\hline A1 & $\begin{array}{l}\text { Disable physical keys of the device if they can acci- } \\
\text { dentally be tapped due to their location }\end{array}$ \\
\hline A2 & $\begin{array}{l}\text { Increase button size or the size of the touch sensitive } \\
\text { area that is triggering an action }\end{array}$ \\
\hline A3 & Provide guide text for using the system \\
\hline A4 & Introduce gestures for interacting to the user \\
\hline A5 & $\begin{array}{l}\text { Enable tapping interaction in addition to swiping and } \\
\text { scrolling interaction. }\end{array}$ \\
\hline A6 & $\begin{array}{l}\text { Choose wording and button labels that are understood } \\
\text { by the target group }\end{array}$ \\
\hline A7 & $\begin{array}{l}\text { Choose icons that fit the mental model of the target } \\
\text { group }\end{array}$ \\
\hline VC1 & Add more coaching in friendship matters \\
\hline VC2 & Do not make the coach too patronising \\
\hline VC3 & $\begin{array}{l}\text { Extend the virtual coach content with tutoring material } \\
\text { so the virtual coach explains the system and helps with } \\
\text { problems }\end{array}$ \\
\hline F1 & $\begin{array}{l}\text { Enable volume control via the application } \\
\text { same interests }\end{array}$ \\
\hline Prote. T- Tablet requirement, A - Tablet application requirement, \\
Virtual coach requirement and F - Friendship function re-
\end{tabular}

In general, there is a large difference between reported and observed ease-of-use. Even though participants reported that they handled the system "reasonably well" in one-on-one sessions (in a scale from 1 'well' to 5 'poorly'), constant support by technical staff was required for guiding how to use the system. Some usability issues were observed, and this pilot provides valuable information for further optimization of the system in later iterations. Participants experienced the design and appearance of the UI positively but some weaknesses were also identified in the simplicity and self-descriptiveness of the interaction. Still, the learnability of the system can be evaluated as good, since the participants quickly learnt to use the system.

The functionality of finding friends through shared interest groups is in line with the finding that people create new contacts through hobbies, and this supports proceeding with expanding the prototype with related functionalities.

\subsection{Ease-of-use of the tablet}

The following findings have been made by observing participants mainly during the one-on-one sessions. Some comments agreeing or disagreeing with the findings are taken from the workshop.

Even though the device was experienced positively in the beginning, it posed some problems during use.

The screen size was mostly evaluated to be "just right" in the one-on-one sessions; only one participant would have wanted to have it in a larger size.

The tablet weight was not experienced as heavy. However, after using the tablet, sooner or later everyone put it on the table. Three out of six one-on-one sessions participants would carry and use the system outside the home, but only one out of six would not use it outside the home in any case. Also, one of the workshop participants stated that she would not take the device with her outside her home: "It is still too heavy to carry it with me". Therefore, the weight of the system has to be considered if the tablet is meant to be carried around ( $\mathrm{T} 1$, first requirements for the tablet device). It should not be significantly heavier than the tested device which was $380 \mathrm{~g}$.

Physical keys on the tablet posed challenges. Some subjects accidentally touched the hard keys on the side that caused the application to exit several times. This error in using the tablet's functionalities could pose a problem in independent use. Therefore, it is important to carefully consider these aspects when choosing a tablet (T2) or modifying the tablet software in a way that certain physical key functionalities are disabled (A1, first requirements for the application).

For some users touch interaction was challenging. This might be due to certain physical changes in greater age affecting the electrical flow. Therefore, it can happen that the interaction with the capacitive touch screen is more challenging. In that case, a conductive stylus would be required. Also, a resistive touch screen might improve the interaction but the required pressure is posing different usability issues. It should be evaluated in more details which technology works best for older users.

One additional negative aspect found in the workshop about the display was that it reflected the light, "It is beautiful but it reflects, I do not like that, it makes it difficult for me to see what is on the screen". Therefore, the reflectivity of the screen should be minimised (T3). This can be done using anti-glare screen protectors. The perceived ease-of-use of them, 
including the effects on touch screen functionality should be investigated in future.

\subsection{Ease-of-use of the application}

The following findings were made mainly during the one-on-one sessions. The application design was generally well liked. However it was not always clear to all users how the system worked and what should be done at each step.

In general legibility was considered to be manageable, and the subjective rating supports these findings since most of the one-on-one session participants found it 'reasonably easy' to read (on a scale from 1 'very easy' to 5 'very difficult'). One of the one-onone sessions would have required larger font. This was also encountered in the workshop: "I need my glasses to read this", "perhaps bigger letters". Therefore, making the system highly accessible, the system should be usable for the widest range of people and also adjusting the font size should be possible. This also supports the 'adaptive system' requirements.

A white font on a black background provides good contrast. However, when the participants were interacting with the UI containing white text on yellow, all of them stated either that there should not be white text on yellow or white text on a colour. This could be due either to low contrast between yellow and white or the tiring effect of the bright yellow due to the high luminance of the LCD screen used. Therefore it is extremely important to provide high contrast between text and background as also the general accessibility guidelines state. The colouring will have to be improved in future versions. The colour scheme was generally experienced positively, "Form is nice, design too". However, one workshop participant stated that "I do not like black". This is a perspective that should be kept in mind e.g. by allowing the user to change the background colour freely, or at least by offering another choice. This is included in the preliminary requirement of 'adaptive system'.

Most participants found the buttons on the touch screen 'difficult' or 'very difficult' to press and two found it 'relatively easy' (on a scale from 1 'very easy' to 5 'very difficult'). This could be due to small button size, but it is not certain to what extent the touch interaction itself was influencing this result. Some of the subjects lack sufficient motoric finger strength and flexibility, and that can affect the interaction. Therefore, bigger buttons or larger touchsensitive areas would be preferable (A2).
All of the participants needed help from the moderator to successfully complete the tasks. The main difficulties that were observed were related to the 'skip' button and the 'confirm' button. The 'skip' button (in the right upper corner in Fig. 4) was not used to continue the process more quickly, as was the purpose of this button. Also, none of the one-on-one session participants confirmed their selection after evaluating the mood on the screen without help from the research assistant and therefore were stuck in the process. They did not realize that they have to confirm the step and did not find the 'confirm' button due to its unexpected position on the screen (right, below the evaluation control Fig. 4). The position of the buttons seems logical, but the users needed pointing out what to do next. Therefore, there should be some guiding text (A3).

Some complex controls which were controlled by scrolling or sliding posed a challenge to the participants. It was not understood by most of the participants how to control the Tacho Control (Figure 4) for evaluating mood and homework at first. Also, scrolling the elements in the group profile carousel for selecting interest groups, an adapted carousel-type interface element, was difficult for most of the participants. They did not know intuitively how to use these controls. However, after a single explanation everyone understood and was able to interact with those controls. These new gestures for interacting may be unfamiliar to the users and they should be introduced, for example, in a tutorial during the first use (A4). Also, the tapping option for interaction should be provided, because it is a more intuitive way to interact and not every older person is easily able to make such fine movements (A5).

Some button labels were not self-descriptive and therefore were not understood by some participants. The label for the 'skip' button, for example, has to be considered, since at least the participants in the testing did not use it. It might be replaced by 'next'. Another option in these situations would be a pop-up describing how the different buttons could help the users. Also, some participants could not distinguish between the different states of the virtual coach, which are 'talk to me now', 'stay in the background' and 'deactivate me'. Most of the users were not sure whether the virtual coach would interrupt them after deactivation. Therefore, it is important to pay attention to the wording in the system in order to be understood by the users (A6).

The participants did not comment spontaneously on the icons. When asked about the icon used to label the "repeat the virtual coach's speech", it was not 
correctly identified by any of the one-on-one session participants. Some participants (two out of six) expected it to be the volume control. Therefore, an icon that meets the users' mental model should be designed (A7).

\subsection{User experience of the virtual coach}

The advice of the virtual coach was perceived 'reasonably useful' (on a scale from 1 'very useful' to 5 'not useful at all') by the one-on-one session participants. However, the advice was expected to contain more content about the coaching in the topic it is targeted to help, namely in friendship matters (VC1, first requirements directly related to virtual coach). Even though coaching and advice was liked in the one-on-one sessions, the feedback from the workshop was the opposite: "I do not like the advice", "the advice is childish; you underestimate older people", "the coach blabbers too much". Therefore, the advice content should be less patronising (VC2) but still provide sufficient guidance in using the system (VC3), since the subjects required external help in every task. It would be important to include the older adult in the development of this advice text in order to ensure a better acceptance. This supports the participatory design in UCD.

The speech of the virtual coach was perceived as understandable by five out of six one-on-one session participants. All of the participants considered it natural and it was well accepted. Even though the volume was set to maximum, some would have preferred a higher volume level. However, they did not know how to alter the volume. At the moment, the volume is controlled by the Galaxy Tab physical keys and it was not clear to the subjects where they were located. Options for making the volume control easier are: an improvement in the device handling tutorials or using software-based volume control within the V2me system (VC5). Also, it is important to the subjects easily to mute or pause the virtual coach's speech (VC6).

Participants did not know how to interact with the virtual coach in the beginning. Some started talking to the screen because the virtual coach was talking itself. Actually this seems to be perfectly natural, but this interaction is not yet supported by the system. However, the participants learnt quickly to interact with the virtual coach by using the tablet screen.

The concept of the virtual coach was accepted, but the guidance should be extended and fine-tuned to meet needs.

\subsection{Usefulness of the system}

The workshop was mainly focused on collecting data about usefulness which are reported in this chapter.

The workshop reinforced the preliminary notion that people make friends through different clubs and hobbies, where people are involved in activity with people of similar interests. Therefore, it is meaningful to find friends through interest groups and responds perfectly to the needs of this target group (F1, first requirement related to friendship functions). It is also good to make friends in an activity (F2). However, no one from the workshop considered the system useful in its current state, and only one participant from the one-on-one sessions. Therefore functionalities in this context have to be expanded and improved. It is also important to note that the participants expected to interact with people in real life and interact less with the technology: "What do I have to do with it? I'd rather have personal contact than technology" This confirms the requirement about 'connecting system'. Also there is a need for local clubs and groups since it was stated that the contact "has to be in the neighbourhood".

\subsection{Acceptance of the system}

The overall acceptance of the current system was rather low. Only three participants (three from the one-on-one sessions, none from the workshop) could imagine using the system in the future if it were improved, and one was determined not to use such a system in any case. This points out that in the next steps, the system should go through considerable development considering the above-mentioned usability aspects as well as the content. As an example of required functions, the participants mentioned games as a fun aspect that would make them use the system more often. This should be considered also for more serious content that could be put into a game-like form to increase acceptance and motivate using V2me more frequently. This also confirms the preliminary requirement about 'entertaining system'.

\section{Discussion}

This is one of the first studies examining tablet use by older adults. To our knowledge there are no comparative research project findings. However, development work in this field is buoyant at the moment. 
At this stage, the prototype was not perceived to decrease loneliness, but based on the study the idea had potential to do so when it is ready.

The present contribution shows that technology usability for older users is, despite the technological advancements, still an issue. Technology use in old age is affected by previous experience of technology, as well as motor and physiological limitations (such as poorer motoric skills and lower skin conductivity). Experience with touch screen devices is generally low, since participants are in an age class that has been introduced to modern communication technology only in later life. Therefore, compared with younger people who have practically grown up with the technology and have good motoric skills, older users are in a very different position. When speaking of the "older user" one should though be well aware of the interindividual differences observed here, since "old age" is far from being a homogenous concept. Moreover, there is plasticity at the individual level allowing for substantial training effects. Apart from all this, it will in any way be important to focus on creating a clear and simple UI instead of using complex features that might jeopardize the simplicity and intuitiveness of the system.

The core idea of finding friends through interest groups was confirmed in this early testing to fit the users' social patterns; hobbies play an important role in meeting people. From here it is good to proceed in expanding the system with new building blocks and fixing the minor usability threats. In the workshop, new potential clubs were discovered that should be included. It is probably never possible to have a list of the "right" clubs, and therefore it has to be considered how to administer these clubs, e.g. by allowing users to create their own. Also, it should be taken into consideration that older people prefer to be less technologically concentrated in their actions, and prefer the human contacts and interactions in real life. Therefore, the system should also promote such activities and events, e.g. through the planned and described calendar and event- planning feature.

Interesting findings resulted as well with respect to the individual conceptions of "friends" and "friendships". "Friends" and "making friends" were considered to have quite a strong meaning, which would include only a small number of people in the social network. Only individuals that have been acquainted for many years were considered as "friends". These findings are in line with predictions derived from the theory of socio-emotional selectivity [12] as well as the social convoy model proposed by Kahn and Antonucci [27]. According to these theories, (a) social networks in old age comprise mostly selectively confident individuals who may help in terms of coping with age-associated strains, and (b) include individuals who have been part of their social network over a life-time. One cannot rule out either that the findings also reflect a cultural phenomenon, and it is worth studying this in the further pilots in countries with different cultural backgrounds.

Some participants of the workshop were determined that not everybody is able to make friends, but that loneliness is instead part of their nature, and that not everyone is considered likeable. In cases where these kinds of perceptions are directed towards the participant, it will be important to offer coaching that can help to change these negative perceptions. Otherwise these might prevent the user from trying to find and make new friends. This is one additional reason why it is important to focus in the next iterations on adding more content from the friendship enrichment programme.

The observational data showed that there were some difficulties in using the system, even though the participants themselves reported it to be rather easy. This discrepancy between reported and observed ease of use is a good example of the need for constant support and advice, since older people might not seek support by themselves.

Individuals reacted very differently to graphical aspects and functionalities, e.g. the virtual coach advice. Due to this high inter-individual variability in preferences, which might in old age be even more prominent than at younger ages, it should be ensured that the system provides high adaptability to serve individual needs which supports the requirement about 'adaptive system' .

Allowing the virtual coach to talk is a controversial point. Even though it makes the virtual coach a little more real, it has certain implications. According to socially shared conventions about social interactions that are represented in individual memory scripts, one tends automatically to reply when one is asked a question. Therefore, when the system talks to you, it is natural that users spontaneously talk back to the system. Thus, the interaction of the virtual coach might cause users to expect that the system is more developed than it is, and that it understands speech. Also, too much talking may be experienced negatively. Therefore, it is important to allow the user to turn the speech synthesis off.

The PSD framework is good for identifying possible persuasive functionalities, even though especially the items in the system credibility support category are difficult to apply in a research project. In light of 
the framework, there could be even more persuasive functions in the system. Some principles might be difficult to apply. For example, the principle for competition in social relationships is questionable. Should you encourage people to pay attention to the number of your friends rather than their quality? If you seek only new friends to add to your system, you might not actually focus on getting to know an individual.

As a further significant result one may highlight that the participants were missing some fun in the system. This is a valid point indeed. A necessary conclusion of this suggestion is to use a more holistic approach and to try to integrate further functionalities that are not limited to getting into and staying in contact with others, but also fulfils other needs of the user, like providing a distraction or raising one's spirits. This aspect can also be useful for encouraging older adults to use this system as it has been used in behavioural change solutions [33].

In future testing we will adhere to the fact that it is often difficult for users to bridge the gap between planned functionalities and those that are actually included. Also brainstorming functionalities are not easy and require strict control and guidance from a moderator in order to keep thoughts on the specific topic. The ideas in the workshop about how to develop the V2me system were mostly technological solutions that participants knew existed for the computer; medical services, games, e-books etc. While these are important and interesting functionalities, they are rarely directly related to decreasing loneliness.

In general, it is also important to consider ethical issues in the interaction between virtual coach and user, especially when the coach is designed to form long-term socio-emotional relationships with the users. Some people question to what extent it is ethical to use such agents to replace human contacts, or whether it can be misleading. However, an increasing amount of research work is investigating the use of these agents in task domains in which human-agent relations actually improve task outcomes, such as counselling, coaching, therapy and care [38]. The fact that the coach is virtual may on the one hand facilitate the coach-user interaction and may help the user to reveal socially less desirable attitudes or behaviour; for example, difficulties in finding new friends may be hard to disclose in direct social contact. On the other hand, there is the risk that a virtual coach may be considered as replacing direct social contact. This is, of course, not the intention of the system. In contrast, V2me explicitly aims at creating a virtual coach who acts both as mediator and as friend. "Me- diator" means here that the virtual coach facilitates direct social contacts, whereas "friend" means that a parasocial relationship is established to motivate the user to engage continuously in the use of the system.

Requirementss derived from this first testing stage will be deployed in subsequent development stages in creating an innovative, easy-to-use and useful technological solution for alleviating loneliness.

\section{Conclusions}

This paper presents the first stages of the development work on the V2me system that is directed towards alleviating loneliness in older adults. The prototype was designed using a UCD process that focuses on the user involvement in the development process. The system was developed for a small-screen ( 7 inch) Android tablet device and tested in one-on-one sessions and a workshop to determine its usability and usefulness.

Our findings conclude that ICT use in old age requires constant end-user involvement during the development and implementation process, constant training and support throughout system use and transfer between the real and the virtual world. These basic requirements have to be fulfilled in order to provide social functionalities and a well-implemented virtual version of the friendship enrichment programme to accomplish the aim of alleviating loneliness in old age.

Finally, the results also showed that the use of the final product will depend on how much it will be able to appeal to the underlying needs for affiliation and socializing. Given the inter-individual variability of motive hierarchies and preferences in age, one has to see as well that not everybody will be inclined to use such a technology, even though he or she may have the functional capacity to do so, because other motives may be more important. The final product will thus be attractive only to those users who experience a pronounced need here, and only if these evaluate the product as useful in serving their needs will there be a potential user community.

\section{Acknowledgements}

Left blank for the blind review. 


\section{References}

[1] Adaptive ambient empowerment of the elderly, www.a2e2.eu, Retrieved: $8^{\text {th }}$ May 2012.

[2] I. Ajzen, The theory of planned behavior, Organizational Behavior and Human Decision Processes 50 (2) (1991), pp. 179-211.

[3] F.M. Alpass and S. Neville, Loneliness, health and depression in older males, Aging \& Mental Health 7(3) (2003), pp. 212 216.

[4] Android. Android user interface guidelines, http://developer.android.com/guide/practices/ui_guidelines/ind ex.htm, Retrieved: 7th October 2011.

[5] J. Askham, D. Ferring and G. Lamura, Personal relationships in later life, in: Ageing in society: An introduction to social gerontology, J. Bond, S.S. Peace, F. Dittmann-Kohli, G.J. Westerhof, eds., Sage, London, UK, 2007, pp. 186-208.

[6] P.J. Auter, Psychometric: TV that talks back: An experimental validation of a parasocial interaction scale, Journal of Broadcasting \& Electronic Media 36(2) (1992), pp. 173-181.

[7] M. Avendano and J.P. Mackenbach, Changes in physical health among older Europeans, in: First Results from the Sur vey of Health, Ageing and Retirement in Europe (2004-2007), Starting the longitudinal dimension. A. Börsch-Supan et al. eds., Mannheim Research Institute for the Economics of Aging, 2008, pp. 118-124.

[8] A. Bandura, Human agency in social cognitive theory, American Psychologist 44(9) (1989), pp. 1175-1184.

[9] A.L. Baylor, Promoting motivation with virtual agents and avatars: Role of visual presence and appearance, Philosophical Transaction of the Royal Society B: Biological Sciences 364(1535) (2009), pp. 3559-3565.

[10]L.F. Berkman and S.L. Syme, Social networks, host resistance, and mortality: A nine-year follow-up study of Alameda County residents, American Journal of Epidemiology 109(2) (1979), pp. 186-204.

[11]J.T. Cacioppo, L.C. Hawkley, L.E. Crawford, J.M. Ernst, M.H. Burleson, R.B. Kowalewski, W.B. Malarkey, E. Van Cauter and G.G. Berntson, Loneliness and health: Potential mechanisms, Psychosomatic Medicine 64(3) (2002), pp. 407-417.

[12] L.L. Carstensen, H.H. Fung and S.T. Charles, Socioemotional selectivity theory and the regulation of emotion in the second half of life, Motivation and Emotion 27(2) (2003), pp, 103-123. doi: 10.1023/A:1024569803230

[13]F.D. Davis, Perceived usefulness, perceived ease of use, and user acceptance of information technology, MIS Quarterly 13(3) (1989), pp. 319-340.

[14] J. de Jong Gierveld and T.G. van Tilburg, Manual of the loneliness scale, VU University Amsterdam, Department of Social Research Methodology, 1999.

[15] P. Dykstra, Older adult loneliness: Myths and realities, European Journal of Ageing 6(2) (2009), pp. 91 -100.

[16] A. Eyck, K. Geerlings, D. Karimova, B. Meerbeek, L. Wang, W. IJsselsteijn, Y. De Kort, M. Roersma and J. Westerink, Effect of a virtual coach on athletes' motivation, Persuasive Technology 3962 (2006), pp. 158-161.

[17] Eldy eldy.eu, Retrieved: $8^{\text {th }}$ May 2012

[18]Eons eons.com, Retrieved $8^{\text {th }}$ May 2012.

[19]D.L. Feltz, Self-confidence and performance, in: Learning, remembering, believing, D. Druckman and R.A. Bjork, eds., National Academy Press, Washington D. C., USA 1994.

[20]M. Fischbein and I. Ajzen, Belief, attitude, intention, and behavior: An introduction to theory and research, AddisonWesley, Reading, MA, USA, 1975.
[21]B. French, D. Tyamagundlu, D.P. Siewiorek, A. Smailagic and D. Ding, Towards a virtual coach for manual wheelchair users, International Symposium on Wearable Computers 12 (2008), pp. 77-80.

[22] J. Frost, N. Boukris and P. Roelofsma Virtual Coaches and Intrinsic Motivation: The Role of Parasocial Interaction, in the 62th Annual Conference of the International Communication Association, Phoenix, USA, May 25, 2012.

[23] T. Hartmann and H. Schramm, The PSI-process scales, a new measure to assess the intensity and breadth of parasocial processes, Communications 33(4) (2008), pp. 385-401.

[24]ISO 9241-210 Ergonomics of human-system interaction -Part 210: Human-centred design for interactive systems.

[25] S.A. Jin, Parasocial interaction with an avatar in second life: A typology of the self and an empirical test of the mediating role of social presence, Presence 19(4) (2010), pp. 331-340.

[26] A.N. Joinson, Looking at, looking up or keeping up with people? Motives and use of Facebook, Proceedings of the twentysixth annual SIGCHI conference on Human factors in computing systems, 2008, pp. 1027-1036.

[27] R.L. Kahn and T.C. Antonucci, Convoys over the life course: Attachment roles and social support, Life-span development and behaviour, P.B. Baltes and O.G. Brim, eds., Academic Press, New York, USA, 1980, pp.253-286.

[28] A.K. Leist and D. Ferring, Technology and aging: Inhibiting and facilitating factors in ICT use, Constructing Ambient Intelligence: AmI 2011 Workshops, R. Wichert, K. Van Laerhoven, and J. Gelissen, eds., Springer, Berlin, Germany, CCIS Series. (2011). pp. 163-165

[29] W.E. Loges and J-Y. Jung, Exploring the digital divide: Internet connectedness and age, Communication Research 28(4), (2001), pp. 536-562.

[30] C.M.S. Martina, N.L. Stevens and G.J. Westerhof, Promotion of self-management in friendship, Aging \& Mental Health iFirst (2011). doi: 10.1080/13607863.2011.596806

[31]J. Meyrowitz, Television and interpersonal behavior: Codes of perception and response. In: Inter media: interpersonal communication in a media world, G. Gumpert and R. Cathcart, eds., Oxford University Press, New York, USA, 1986.

[32] K. Murata, H. Iwase, Usability of touch-panel interfaces for older adults, Human Factors: The Journal of the Human Factors and Ergonomics Society 47(4) (2005), pp. 767-776.

[33] J. Navyn, S.S. Intille, K. Larson, Embedding behavior modification strategies into a consumer electronic device. A case study, in: Lecture Notes in Computer Science, UBICOM 2006. Ubiquitous computing, P. Dourish, A. Friday, eds, Springer, Berlin, Germany 4206 (2006), pp. 297-314.

[34]J. Nielsen, Usability engineering, AP Professional Ltd, London, UK, 1993.

[35]H. Oinas-Kukkonen and M. Harjumaa, Persuasive Systems Design: Key issues, Process Model, and System Features, in Communications of the Association for Infromation Systems, 24(1) (2009), pp. 485-500.

[36] Oldkids oldkids.cn, Retrieved: $8^{\text {th }}$ May 2012.

[37]B. Otjacques, M. Krier, F. Feltz, D. Ferring and M. Hoffmann, User-centered activity management system for elderly people, $3 r d$ International Conference on Pervasive Computing Technologies for Healthcare 2009 (Pervasive Health 2009) IEEE Computer Society Editions, London, UK,.

[38] Relational agents group www.relationalagents.com, Retrieved: $28^{\text {th }}$ May 2012.

[39] B.M. Rosson and J.M. Carroll, Usability engineering: Scenario-based development of human-computer interaction, Morgan Kaufmann, Redwood City, CA, USA, 2001. 
[40]R.B. Rubin and M.P. McHugh, Development of parasocial interaction relationships, Journal of Broadcasting \& Electronic Media 31(3) (1987), pp. 279-292.

[41]A. Sears and J.A. Jacko, eds., The human-computer interaction handbook. Fundamentals, evolving technologies, and emerging applications, 2nd edition, Lawrence Erlbaum Associates, Mahwah, NJ, USA, 2007.

[42] N.L. Stevens, C.M.S. Martina and G.J. Westerhof, Meeting the need to belong: Predicting effects of a friendship enrichment program for older women, The Gerontologist 46(4) (2006), pp. 495-502. doi: 10.1093/geront/46.4.495

[43] Virtual coach reaches out to me, www.v2me.org, Retrieved: $8^{\text {th }}$ May 2012

[44]G.C. Wenger, R. Davies, S. Shahtahmasebi and A. Scott, Social isolation and loneliness in old age: Review and model refinement, Ageing and Society 16(3) (1996), pp. 333-358.

[45] J. Westerink, M. de Jager, J. Van Herk, Y. de Kort, W. IJsselstein, M. Van Boven, R. Jacobs, Y. van Laarhoven and E. Van der Wal, The influence of virtual coaching on social presence and motivation in home fitnessing, Psychology and Health 19(Suppl. 1) (2004), pp. 181-182.

[46] R. Wood and A. Bandura, Social cognitive theory of organizational management, Academy of Management Review 14(3) (1989), pp. 361-384. 